\title{
Statement From the International Scientific Summer School Collaboration Group
}

Biomedical journals have become aware of the increased need for receiving manuscripts of higher quality in respect of research design and questions investigated. During the years of conducting International Scientific Summer Schools (ISSS), the number of journals that recognized ISSS as a promising way to address this issue has grown. The journals supporting the ISSS initiative from the first ISSS held in 2006 were

- Journal of Electrocardiology

- Croatian Medical Journal

- The Anatolian Journal of Cardiology

The journals joining the ISSS collaboration group currently are

- Balkan Medical Journal

- Monitor of Medicine of Slovak Medical Society

- Lietuvos bendrosios praktikos gydytojas (Lithuanian Family Doctor)

- MEDICINA

- Hippokratia

By publishing this statement, the journals joining the ISSS collaboration group accept its goals and values, which are as follows:

\section{Goals}

- to sponsor and promote the ISSS research practicum;

- to support the ISSS training in designing methodologically sound research projects for young researchers and their mentors, especially those from countries where teaching research methodology and academic writing is not part of university curricula;

- to train young researchers and mentors as their potential authors able to submit manuscripts of high quality for publication;

- to consider ISSS-trained young researchers potential reviewers, able to provide high quality reviews of manuscripts;

- to create a platform for exchange of ideas and opinions between editors on areas of their common interest;

\footnotetext{
Values

- international collaboration and networking;

- interdisciplinary approach to research;

- high level of professionalism in research.
}

By joining the ISSS collaboration group, journals may increase their international visibility and contribute to increasing the quality of research performed.

In addition, the journals agree to:

- publish the announcement of the forthcoming ISSS events;

- publish the summaries on recent ISSS events;

- request for manuscript reviews by ISSS participants, as needed;

- organize and sponsor ISSS events in their countries, if possible;

- recommend participants and faculty to ISSS event.

\section{International Scientific Summer School}

\section{Short description}

The Summer School provides an interdisciplinary international environment for training skills required for preparing research study protocols, scientific manuscript and international collaboration. During four days, the participants experience a process of elaborating and presenting common research project. This process includes defining a research topic of common interest, selecting an adequate study design, selecting an adequate method of data collection, analysis and interpretation, and developing a feasible study plan and timeline for the projects, including the preparation of a research paper.

\section{Eligible participants and methods}

Eligible participants are undergraduate and postgraduate biomedical students and researchers from biomedical research in medicine, physiology, biophysics, engineering, computer science, etc. The participation is open also for mentors who would like to share the experience of this learning method.

The course consists of four workshops and is based on the Research Practicum of the Duke University, Durham, NC, USA. It combines plenary and small group discussions, project development and class presentation, and discussion on publishing scientific papers with representatives of medical scientific journals. Up to 20-25 participants work in groups to ensure an intensive interaction between participants and faculty. There is approximately equal number of local and foreign participants.

In the period before the Summer School, participants are recommended to read the Outcomes Research Practicum 
protocols and the Summer School Tutorial for the overall information.

\section{Goals}

- Develop skills to carry out research projects, based on a practical, problem-based approach;

Journal of Electrocardiology

Editors: Galen Wagner, Ljuba Bacharova

ISSS Faculty

Sasa Misak
- Increase communication skills, including the skills in argumentation, negotiation and critical appraisal in English language;

- Develop skills in international research team building and networking, and establish enjoyable cross discipline/cross cultural collaboration;

- Encourage researchers to publish scientific papers.

The Anatolian Journal of Cardiology

Editors: Bilgin Timuralp, Gulmira Kudaiberdieva

Balkan Medical Journal

Editors: Cem Uzun, Mustafa Inan

This statement was published with the mutual decision and permission of the abovementioned journals and their editors. 